\title{
Effect of Warm Rolling on Microstructure and Mechanical Properties of Twin-roll Casted ZK60 Alloy Sheets
}

\author{
Xibing Gonga*, Wentao Gong ${ }^{b}$, Suk Bong Kang ${ }^{c}$, Jae Hyung Cho ${ }^{c}$ \\ ${ }^{a}$ Mechanical Engineering Department, The University of Alabama, Tuscaloosa, Alabama, 35487, USA \\ ${ }^{b}$ School of Mechanical and Automotive Engineering, South China University of Technology, \\ Guangzhou 510640, China \\ 'Korea Institute of Materials Science, Changwon 641010, Republic of Korea
}

Received: August 24, 2014; Revised: March 19, 2015

\begin{abstract}
In this study, ZK60 magnesium alloy strips were produced by twin roll casting (TRC) and then subjected to warm rolling at the temperature of $300{ }^{\circ} \mathrm{C}$ and $350^{\circ} \mathrm{C}$. Rolled sheets related to different rolling reductions were prepared after sequential warm rolling with the rolling speed of $5 \mathrm{~m} / \mathrm{min}$. Microstructures, texture, hardness, tensile properties of the rolled sheets with different rolling reductions were studied experimentally. It has been found that grain refinement occurs actively during the warm rolling. Also, high density of shear bands were observed in the rolled sheets. The warm rolling sheet presents strong (0002) basal texture. In addition, the increase of the rolling reduction results in the improvement of the mechanical properties.
\end{abstract}

Keywords: magnesium alloy, twin roll casting, warm rolling, microstructure, mechanical properties

\section{Introduction}

Magnesium (Mg) alloys are promising structural light materials due to their high specific strength, high specific stiffness, and so on. $\mathrm{Mg}$ and its alloys have been widely applied in the industrial area ${ }^{1}$. However, the strength of $\mathrm{Mg}$ alloys is relatively low at room temperature and the manufacturing cost is high. These two factors limit the wide industrial applications of $\mathrm{Mg}$ alloys ${ }^{2}$.

Recently, twin roll casting (TRC) technology has been developed to manufacture $\mathrm{Mg}$ alloy sheets economically while maintaining a high level of quality ${ }^{2,3}$. TRC combines casting and hot rolling into a single step and provides much faster solidification rates than conventional casting. The relatively fast solidification rate of TRC has beneficial effects on the microstructure, such as reducing segregation and refining microstructural features ${ }^{2-4}$. Owing to its many advantages, TRC has become more and more popular in the industrial applications. For the producing of thin $\mathrm{Mg}$ alloy sheets, the subsequent warm rolling on TRC strips has the ability to achieve $\mathrm{Mg}$ alloy sheet with high mechanical properties ${ }^{2}$. Chen et al. studied the microstructure and mechanical properties of Mg-4.5Al-1.0Zn alloy sheets produced by TRC and sequential warm rolling ${ }^{4}$. The $\mathrm{Mg}$ alloy sheets showed higher strength but lower elongation after sequential warm rolling, while the post annealing after warm rolling greatly improve the formality of the $\mathrm{Mg}$ sheets. Wang et al. investigated the warm rolling on Mg-Al-Mn-Ca TRC sheets and found that the present TRC sheet presents superior tensile strength and comparative elongation compared to commercial ingot cast one, suggesting the possibility of the development of wrought $\mathrm{Mg}$ alloy sheets by TRC ${ }^{5}$. The microstructural evolution during warm rolling and subsequent annealing

*e-mail: xgong2@crimson.ua.edu as well as the resulting tensile properties were analyzed and discussed. Kurz et al. ${ }^{6}$ studied the influence of process parameters on AZ31 TRC strip. It is found that optimization of process parameters of TRC offers the possibility to produce high quality sheet material. Ucuncuoglu et al. ${ }^{7}$ studied the warm rolling on the AZ31 Mg alloy and it is found that the grain size of $19 \mu \mathrm{m}$ for the TRC strip is reduced to $10 \mu \mathrm{m}$ after rolling. Chen et al. ${ }^{8}$ studied the texture of the $\mathrm{Mg}$ alloy processed by TRC and warm rolling. The warm rolled ZK60 alloy sheet exhibited strong (0002) pole texture, the intensity of (0002) pole figure decreases with the increasing of rolling temperature and the basal pole tilted slightly to the transverse direction after warm rolling.

The present research is to explore the effect of warm rolling on the microstructures, textures and mechanical properties of a TRC processed ZK60 alloy. The research also examines the microstructure and mechanical properties of the rolled sheets with different rolling reductions. The studies would provide novel method to improve mechanical properties of the ZK60 TRC strip.

\section{Experimental}

The chemical composition of ZK60 alloy is present in Table $1^{9}$. A horizontal type twin roll caster with water-cooling system was used to manufacture ZK60 Mg alloy strip. A pair of copper alloy rollers with $300 \mathrm{~mm}$ in diameter were used for the horizontal type twin roll caster. Molten alloy was heated to $720^{\circ} \mathrm{C}$ and then flowed down into the casting tundish. The molten metal contacted with cooled rollers and was rolled between the upper and lower rollers. The rolling speed was $5 \mathrm{~m} / \mathrm{min}$ and the roller gap was $3 \mathrm{~mm}$. A strip with $4.3 \mathrm{~mm}$ thick, $100 \mathrm{~mm}$ wide and $10 \mathrm{~m}$ long was manufactured. The 
Table 1. Chemical Composition of ZK60 alloy (Weight Percent) 9

\begin{tabular}{cccccccccc}
\hline Al & Zn & Mn & Si & Fe & Cu & Ni & Ca & Zr & Mg \\
\hline 0.01 & 5.47 & 0.009 & 0.022 & 0.003 & 0.003 & 0.007 & 0.005 & 0.58 & Bal. \\
\hline
\end{tabular}

isothermal warm rolling was done by heating the rollers to $250{ }^{\circ} \mathrm{C}$, in which the as-cast strip was allowed to cool to room temperature, then reheated to $350{ }^{\circ} \mathrm{C}$ for $30 \mathrm{~min}$, and rolled at that temperature and reheated again to $350{ }^{\circ} \mathrm{C}$ for $5 \mathrm{~min}$. This process was continually carried out over 6 pass to reduce the strip thickness from $4.3 \mathrm{~mm}$ to $1.0 \mathrm{~mm}$, and then rolled at the temperature of $300{ }^{\circ} \mathrm{C}$ and reheated again to this temperature for $5 \mathrm{~min}$ (intermediate annealing), the strip thickness was rolled from $1.0 \mathrm{~mm}$ to the final thickness of $0.5 \mathrm{~mm}$. The rolling reduction ratio of $30 \%$ per pass was made for warm rolling.

Fabricated ZK60 samples were prepared for microstructural observation with standard metallographic procedures including sectioning, mounting, grinding with $\mathrm{SiC}$ paper up to grit size of 1000. Specimens closed to the middle of the transverse direction (TD) plane of the rolled sheets were used for analysis. To reveal the microstructures, polished specimens were then etched with a solution of picric acid $(5 \mathrm{~g})$, acetic acid $(5 \mathrm{ml})$, distilled water $(10 \mathrm{ml})$, and ethanol $(100 \mathrm{ml})$. The etched metallographic samples were then examined using optical microscope (OM). Transmission electron microscopy (TEM) observations were conducted for the middle region of the final rolled sheet using a JEM-2100F TEM operating at $200 \mathrm{kV}$. Thin foils were prepared by a twin-jet electron-polisher using a solution of thin foils were prepared by a twin-jet electron-polisher using a solution of $\mathrm{HNO}_{3}(10 \%)$, glycerin (30\%) and methanol (60\%). (0002) and (10-10) pole figures of the final sheets were measured at the mid-thickness by X-ray diffraction (XRD) using an $\mathrm{X}$ ' Pert Pro MRD equipment in the reflection mode with $\mathrm{Cu}$ Ka radiation. The samples for the XRD measurements were prepared with the normal direction (ND) of the measurement plane. The values reported for Vickers microhardness (HV) represented the average of seven separate measurements taken at randomly selected points using a load of $100 \mathrm{~g}$ for $15 \mathrm{~s}$. Tensile tests for the rolled sheets were carried out according to the ASTM E8 standard, using samples with a gauge length of $12.5 \mathrm{~mm}$ and a width of $3 \mathrm{~mm}$ along the rolling direction (RD). The tests were conducted on a standard universal testing machine (Instron 4206) at room temperature with a normal strain rate of about $2 \times 10^{-3} \mathrm{~s}^{-1}$. To ensure reproducibility of the tensile results, three specimens were tested in each case.

\section{Results and Discussion}

\subsection{Microstructure of the TRC strip}

The surface of the TRC strip was smooth and did not react with oxygen in the air. Figure 1 represents the microstructure of the ZK60 TRC strip. During TRC, the microstructure is primary defined by the rapid cooling. The microstructure of TRC strip presents the combination of dendrite structure, and the eutectics and intermetallic compounds located in the interdendritic region, as can be seen in Figure 1a. After the subsequent annealing for homogenization, the eutectic

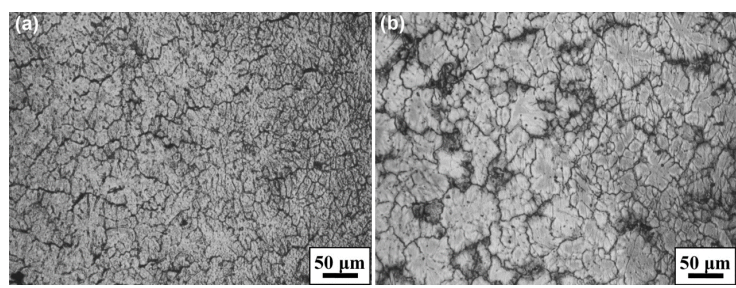

Figure 1. Microstructures of TRC ZK60 alloys by OM: (a) as-cast strip, and (b) TRC and then annealed.

phase is dissolved, and the material was homogenized and a fine grain structure develops (Figure 1b). The dendritic structure is $\mathrm{Mg}-\mathrm{Zn}$ phase, which is the main source of the age hardening behavior of ZK60 alloy ${ }^{10}$. The TRC strip shows different microstructure compared with conventional casting samples. According to the study by Wang et al., casted ZK60 alloy shows coarser and equiaxed grains and some second eutectics and intermetallic compounds are also found along the grain boundaries or the interior of grains ${ }^{11}$. However, it is difficult to find equiaxed grains for the TRC strip. It is well known that the cooling rate in solidification has a great influence on the microstructure and the mechanical properties of alloys ${ }^{12}$. An increase in cooling rate results in a reduction in dendrite arm spacing, grain size, and subsequently an improvement in mechanical properties. Yang et al. studied the effect of cooling rate on the microstructure of ZK60 alloy, in range of 0.2 to $100 \mathrm{~K} / \mathrm{s}$, and showed that as the cooling rate increases the grain size, secondary dendrite arm spacing, and the primary dendrite-arm spacing sharply decrease ${ }^{11}$. It is also reported that the phase distribution also undergoes changes with different cooling rates. Lin et al. investigated the solidification structures of AZ91 Mg alloy has shown that that as the cooling rate increases, the quantity of the solid-solution phase increases and the fraction of secondary phase, $\mathrm{Mg}_{17} \mathrm{Al}_{12}$, decreases ${ }^{13}$. Besides the finer microstructure, TRC strips are also found to have less segregation, uniform distribution of grain size, grain refinement owing the higher cooling rate ${ }^{14}$.

\subsection{Microstructure and texture of rolled sheets}

Warm rolling was conducted to process the thin ZK60 sheets to enhance the mechanical properties of $\mathrm{Mg}$ alloy. Different rolling reductions were achieved with different rolling passes. Figure 2 shows the microstructure of the rolled sheets with different rolling reductions: $37 \%, 77 \%, 83 \%$, and $88 \%$. Generally, the warm rolling changed the shape of grains and greatly increased the total grain boundary area. The new grain boundary area is created with the incorporation of dislocations which were continuously generated during the deformation process. For the sheet with rolling reduction of $37 \%$, the dendritic structure is broken but coarse grain structure is still existed with fine grains (Figure 2a). The specimen with the rolling reduction of $77 \%$ consists of 
elongated grains and microstructure is changed to fibrous structure. A relatively low density of shear bands is observed together with very little recrystallized grains (see Figure 2b). The grains have been elongated to be thin and long bands. While after the 8 th rolling pass (rolling reduction of $83 \%$ ), the specimen is characterized by fine well-delineated grain boundary together with dynamic recrystallized (DRX) grains, as can be seen from Figure 2c. A high density of deformation bands were observed with a low density of fine equiaxed recrystallized grains in some local areas. It is evident that grain refinement proceeded during warm rolling but grain structure was not homogeneous. The $88 \%$ rolling reduction sheet shows more completed recrystallization for its severer plastic deformation and stored energy which is an important factor to recrystallization (Figure $2 \mathrm{~d}$ ). Chen et al. investigated the effect of rolling temperature on the microstructure of ZK60 alloy. It is that low temperature warm rolling results in higher density of shear bands (Figure 2a), and the density of shear bands decreases with the increasing of the rolling temperature ${ }^{3}$.

It is also noted that intermediate annealing was conducted and the rolled sheets were annealed in the same temperature as the rolling temperature for about 5 minutes to reduce the inner stresses. Figure 3 presents the microstructure of the rolled sheet with rolling reduction of $63 \%$ (Figure $3 a$ ) and after subsequent intermediate annealing (Figure 3b). Fine grains are found along the shear bands after the intermediate annealing, indicating that nucleation and grain growth during static recrystallization (SRX) occurred. The grain refinement

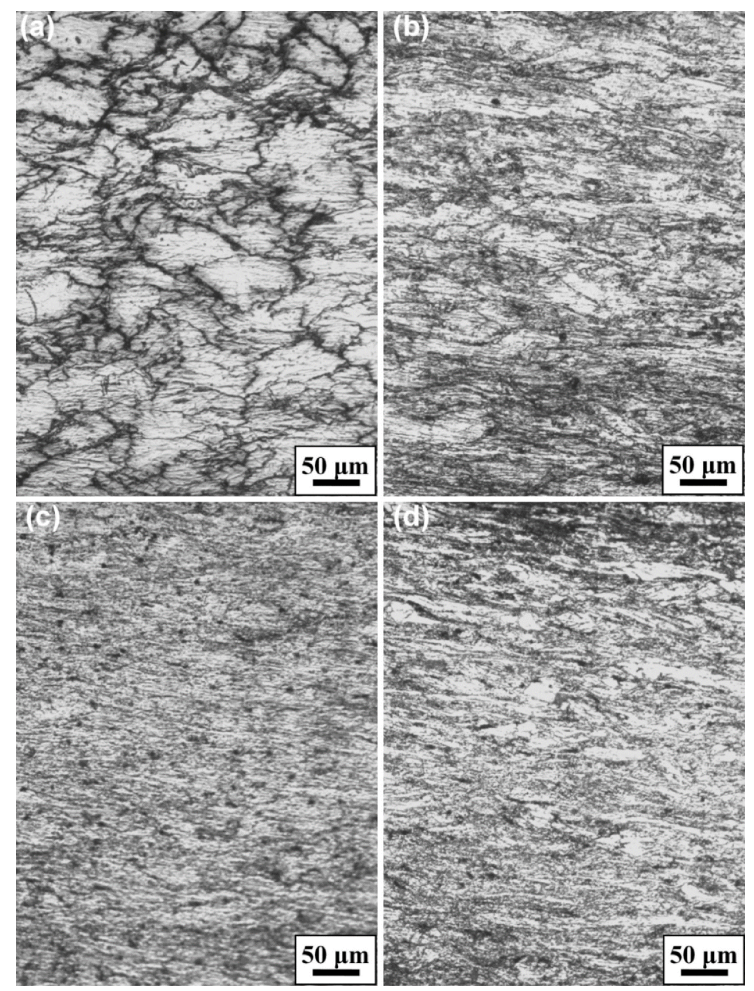

Figure 2. Microstructure of TRC ZK60 alloy rolled sheets: (a) 2 pass and rolling reduction of $37 \%$, (b) 6 pass and rolling reduction of $77 \%$, (c) 8 pass and rolling reduction of $83 \%$, (d) 10 pass and rolling reduction of $88 \%$. mainly occurs in the shear bands because the main portion of the plastic deformation is thought to take place in the shear bands during rolling. It indicates that more intense plastic deformation concentrates on the shear bands during the rolling process ${ }^{2}$. After the rolling, the fine microstructure is achieved as a result of the severe plastic deformation and recrystallization. Figure 4 shows the TEM micrograph of the final rolled sheet. Shear bands or highly localized deformation are seen with the width around 150-200 nm. In addition, high density of dislocation is observed as well. The piled dislocations have the tendency to restructure to form new grains by SRX or DRX ${ }^{4}$.

Figure 5 presents the incomplete (0002) and (10-10) pole figures of the rolled sheets. The mid-layer of the TRC strip and rolled sheets was observed. The investigation of crystal orientation was carried out by estimating the magnitude of peak values, which is a ratio of diffraction intensity. It is observed that the rolled sheets exhibit strong (0002) basal texture, which is typical for rolled $\mathrm{Mg}$ alloy sheets. The strong basal texture will affect the mechanical properties because the crystallography orientation has a significant relationship to slip and twining systems which corresponding to the deformation modes ${ }^{15}$.

Strong basal texture is also found by other research on the warm rolling of $\mathrm{Mg}$ alloys. Jeong \& $\mathrm{Ha}^{16}$ studied the texture development of the warm rolled AZ31 Mg alloy. The major texture of all the specimens can be expressed by (0002) fiber texture. It is also found that the texture of the warm rolled sheet showed that the basal pole tilted

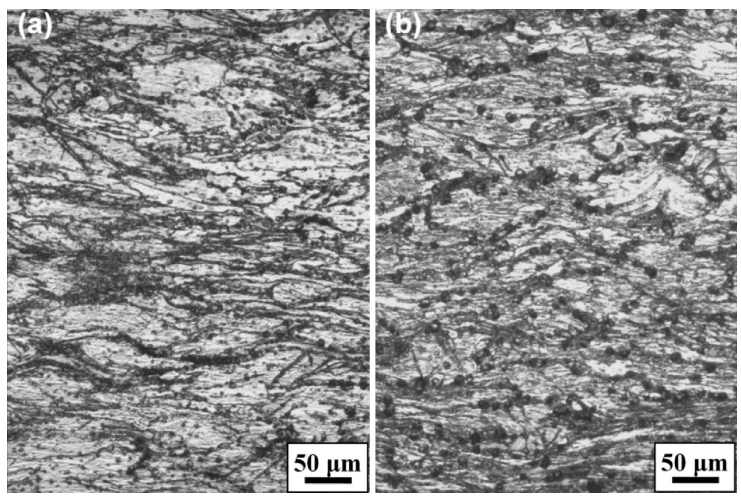

Figure 3. Microstructure of the rolled sheet: (a) rolling reduction of $63 \%$ and (b) after intermediate annealed sheet.

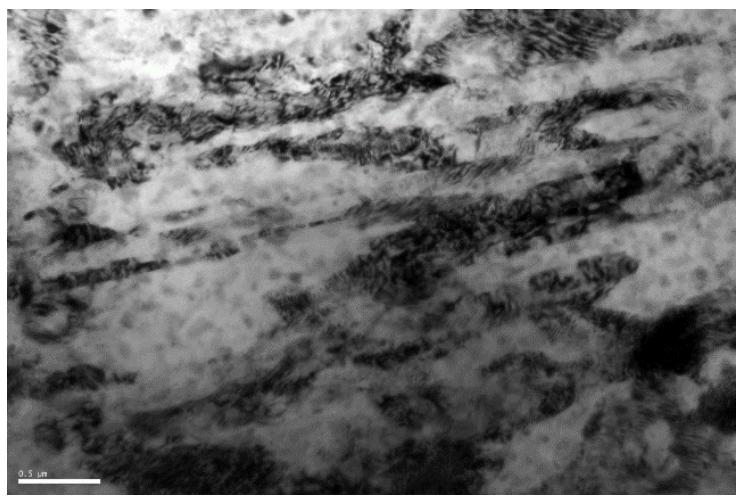

Figure 4. TEM micrograph of the rolled sheet. 
slightly to the transverse direction. Ucuncuoglu et al. ${ }^{7}$ also studied the texture evolution during the rolling of TRC strip. It is found that rolling generally gives rise to a strong basal texture, which exhibits low press formability at near room temperature because the basal slip systems become inactive. This induces the high normal anisotropy in sheet and increases the difficulty in deformation accompanied with thickness reduction, and consequently leads to a very limited formability near room temperature. The strong basal texture is thought to result in the enhancement of strength of $\mathrm{Mg}$ alloys sheets.

\subsection{Mechanical properties of the rolled sheets}

Figure 6 shows the effect of the rolling reduction amount on the Vickers Hardness HV for ZK60 alloy sheets produced by TRC and sequential warm rolling. Generally, the hardness of the as rolled sheets has greatly improved with the increase of rolling reduction. The hardness of TRC strip is HV 71.5, while the hardness is increased to HV 86 for the final rolled sheet. The tensile properties of the rolled sheets were also tested, as can be shown in Figure 7. For the rolled sheets after 6 passes rolling, the yield strength, tensile strength and elongation are $295 \mathrm{MPa}, 340 \mathrm{MPa}$ and 3.2\%, respectively; while the corresponding values for the final rolled sheet are $288 \mathrm{MPa}, 350 \mathrm{MPa}$ and $6.2 \%$, respectively. Compared with the rolled sheets with 6 passes rolling, the mechanical properties of the final rolled sheets are improved generally, especially for the elongation. It is seen that the mechanical properties of experimental alloy are improved after further plastic deformation. The great improvement of the hardness could be attributed to the strain hardening effect and grain refinement.

The rolling process will promote the formation of microstructures with higher dislocation density and finer grain size. The generated high-density dislocations will be able to act as further obstacles to dislocation motion, resulting a strengthening effect. In addition, the mechanical properties (e.g., strength) of crystalline materials have been widely shown to have a positive dependence on their mean size ${ }^{17-21}$. This could be a reasonable explanation of the significantly enhanced mechanical properties of the final rolled sheet compared to that of the TRC strip.

It is note that, although the maximum elongation of $6.2 \%$ is still not ideal for industrial application. This is because the stress concentration is difficult to be relaxed at increased strain rates due to increased severity of dislocation pile-up

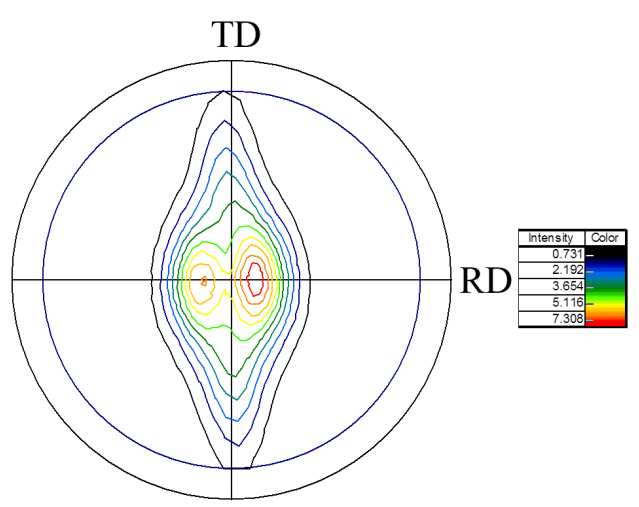

Max: 8.0

(a)

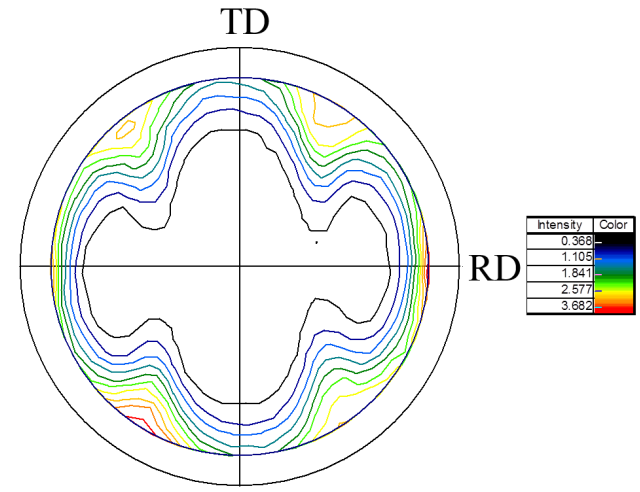

Max: 4.1

(b)

Figure 5. Incomplete pole figure measured for the ZK60 sheets: (a) (0002) and (b) (10-10).

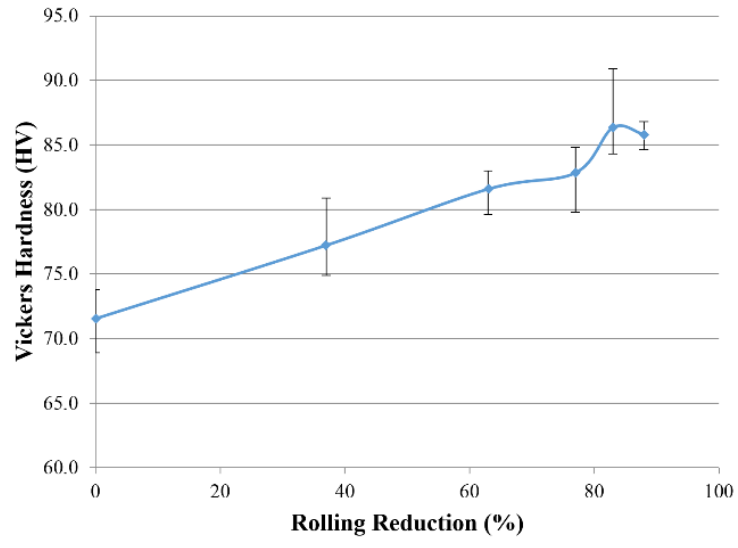

Figure 6. Vickers hardness of rolled sheets with different rolling reductions.

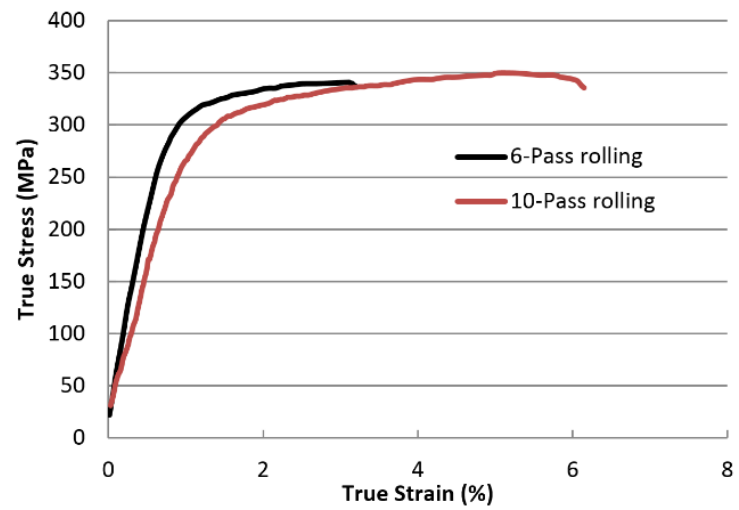

Figure 7. Strain-stress of rolled sheets. 
and depressed DRX, thus deteriorating the accommodating ability and ductility ${ }^{22}$. The further improvement of the $\mathrm{Mg}$ alloy sheet could be achieved by heat treatment, such as annealing.

\section{Conclusions}

In the present study, ZK60 Mg alloy sheets with the thickness of $0.5 \mathrm{~mm}$ were processed by twin roll casting at $720^{\circ} \mathrm{C}$ and subsequent warm rolling at $300-350{ }^{\circ} \mathrm{C}$ successfully. The effects of the warm rolling on the microstructure and mechanical properties were experimentally studied. The major findings are summarized as follows:

(1) The microstructure of rolled sheets consists of fibrous structure with elongated grains, and shear bands along the

\section{References}

1. Harandi SE, Mirshahi M, Koleini S, Idris MH, Jafari $\mathrm{H}$ and Kadir MRA. Effect of calcium content on the microstructure, hardness and in-vitro corrosion behavior of biodegradable Mg-Ca binary alloy. Materials Research. 2013; 16(1):11-18. http://dx.doi.org/10.1590/S1516-14392012005000151.

2. Gong X, Kang SB, Li S and Cho JH. Enhanced plasticity of twin-roll cast ZK60 magnesium alloy through differential speed rolling. Materials \& Design. 2009; 30(9):3345-3350. http:// dx.doi.org/10.1016/j.matdes.2009.03.040.

3. Chen HM, Kang SB, Yu HS, Kim HW and Min GH. Microstructure and mechanical properties of Mg-4.5Al-1.0Zn alloy sheets produced by twin roll casting and sequential warm rolling. Materials Science and Engineering A. 2008; 492(1-2):317-326. http://dx.doi.org/10.1016/j.msea.2008.03.035.

4. Gong X, Li H, Kang SB, Cho JH and Li S. Microstructure and mechanical properties of twin-roll cast Mg-4.5Al-1.0Zn sheets processed by differential speed rolling. Materials \& Design. 2010; 31(3):1581-1587. http://dx.doi.org/10.1016/j. matdes.2009.09.021.

5. Wang YN, Kang SB and Cho JH. Microstructure and mechanical properties of Mg-Al-Mn-Ca alloy sheet produced by twin roll casting and sequential warm rolling. Journal of Alloys and Compounds. 2011; 509(3):704-711. http://dx.doi.org/10.1016/j. jallcom.2010.07.183.

6. Kurz G, Bohlen J, Letzig D and Kainer KU. Influence of Process Parameters on Twin Roll Cast Strip of the Alloy AZ31. Materials Science Forum. 2013; 765:205-209. http://dx.doi. org/10.4028/www.scientific.net/MSF.765.205.

7. Ucuncuoglu S, Ekerim A, Secgin GO and Duygulu O. Effect of asymmetric rolling process on the microstructure, mechanical properties and texture of AZ31 magnesium alloys sheets produced by twin roll casting technique. Journal of Magnesium and Alloys. 2014; 2(1):92-98. http://dx.doi.org/10.1016/j.jma.2014.02.001.

8. Chen HM, Yu HS, Kang SB, Min GH and Jin YX. Effect of rolling temperature on microstructure and texture of twin roll cast ZK60 magnesium alloy. Transactions of Nonferrous Metals Society of China. 2010; 20(11):2086-2091. http://dx.doi. org/10.1016/S1003-6326(09)60422-2.

9. Cho JH, Chen HM, Choi SH, Kim HW and Kang SB. Aging effect on texture evolution during warm rolling of ZK60 alloys fabricated by twin-roll casting. Metallurgical and Materials Transactions A: Physical Metallurgy and Materials Science. 2010; 41(10):2575-2583. http://dx.doi.org/10.1007/s11661010-0336-x.

10. Kang SB, Cho JH, Kim HW and Jin YM. Effect of heat treatment on microstructure and mechanical properties in ZK60 alloy sheet. Materials Science Forum. 2008; 567-568:361-364. http:// dx.doi.org/10.4028/www.scientific.net/MSF.567-568.361. rolling direction after warm rolled. Increasing the thickness reduction will lead to finer structure of the sheets.

(2) Dynamic recrystallization could be found during the warm rolling process. And many fine recrystallized grain could be observed in the shear band area.

(3) The warm rolling sheets show a strong (0002) basal texture. The increase of rolling reduction in warm rolling was found to strengthen the basal texture.

(4) Generally, with the increase of the rolling reduction, both the hardness and tensile strength become higher. The rolling process plays an important role in controlling microstructures, enhancing mechanical properties, and in turn, improving the workability of TRC Mg alloy.

11. Yang C, Zhang D, Ding P, Peng J and Chen X. Effects of cooling rate on solidification microstructure of ZK60 magnesium alloy. Materials Science Forum. 2005; 488-489:295-298. http://dx.doi. org/10.4028/www.scientific.net/MSF.488-489.295.

12. Liu W, Ma J, Yang G and Kovacevic R. Hybrid laser-arc welding of advanced high-strength steel. Journal of Materials Processing Technology. 2014; 214(12):2823-2833. http://dx.doi. org/10.1016/j.jmatprotec.2014.06.018.

13. Yang L, Feng H, Qiu KQ, Chen LJ and Liu Z. Effect of cooling rate on microstructure and compressive performance of AZ91 magnesium alloy. Transactions of the Nonferrous Metals Society of China. 2006; 16:1698-1702.

14. Wang S, Kang SB and Cho J. Effect of hot compression and annealing on microstructure evolution of ZK60 magnesium alloys. Journal of Materials Science. 2009; 44(20):5475-5484. http://dx.doi.org/10.1007/s10853-009-3762-7.

15. Wang YN and Huang JC. Texture analysis in hexagonal materials. Materials Chemistry and Physics. 2003; 81(1):11-26. http:// dx.doi.org/10.1016/S0254-0584(03)00168-8.

16. Jeong HT and Ha TK. Texture development in a warm rolled AZ31 magnesium alloy. Journal of Materials Processing Technology. 2007; 187:559-561. http://dx.doi.org/10.1016/j. jmatprotec.2006.11.084.

17. Valiev RZ and Langdon TG. Principles of equal-channel angular pressing as a processing tool for grain refinement. Progress in Materials Science. 2006; 51(7):881-981. http:// dx.doi.org/10.1016/j.pmatsci.2006.02.003.

18. Chang LL, Wang YN, Zhao X and Huang JC. Microstructure and mechanical properties in an AZ31 magnesium alloy sheet fabricated by asymmetric hot extrusion. Materials Science and Engineering A. 2008; 496(1-2):512-516. http://dx.doi. org/10.1016/j.msea.2008.06.015.

19. Gong X, Kang SB, Cho JH and Li S. Effect of Annealing on Microstructure and Mechanical Properties of ZK60 Magnesium Alloy Sheets Processed by Twin-roll Cast and Differential Speed Rolling. Materials Characterization. 2014; 1:1-12.

20. Wu Z, Bei H, Otto F, Pharr GM and George EP. Recovery, recrystallization, grain growth and phase stability of a family of FCC-structured multi-component equiatomic solid solution alloys. Intermetallics. 2014; 46:131-140. http://dx.doi.org/10.1016/j. intermet.2013.10.024.

21. Wu Z, Bei H, Pharr GM and George EP. Temperature dependence of the mechanical properties of equiatomic solid solution alloys with face-centered cubic crystal structures. Acta Materialia. 2014; 81:428-441. http://dx.doi.org/10.1016/j.actamat.2014.08.026.

22. Yin DL, Zhang KF, Wang GF and Han WB. Warm deformation behavior of hot-rolled AZ31 Mg alloy. Materials Science and Engineering A. 2005; 392(1-2):320-325. http://dx.doi. org/10.1016/j.msea.2004.09.039. 